\title{
LEITURA EM SALA DE AULA DE CIÊNCIAS COMO UMA PRÁTICA SOCIAL DIALÓGICA E PEDAGÓGICA
}

\author{
Célio da Silveira Júnior ${ }^{*}$ \\ Maria Emília Caixeta de Castro Lima** \\ Andréa Horta Machado***
}

RESUMO: Neste trabalho, com base nos fundamentos da perspectiva histórico-cultural do desenvolvimento humano, enfocamos a problemática da mediação pedagógica da leitura de textos didáticos de ciências em sala de aula. Argumentamos a favor da leitura de textos de ciências, para se aprender ciências, e sobre ao papel central que a mediação docente desempenha nesse processo. A partir de dados de uma mediação de leitura específica, discutimos as ações do professor frente às contrapalavras dos estudantes que emergiram durante uma leitura compartilhada. Concluímos que a mediação constituiu-se como uma prática social dialógica (pela palavra) e pedagógica (pelo outro), que contribui para o processo de compreensão de/sobre ciências pelos estudantes, além de resultarem um novo texto coletivamente construído pela oferta de contrapalavras.

Palavras-chave:Mediação.Leitura.Ensino e aprendizagem de ciências.

\section{LEER EM CLASES DE CIENCIA COMO UNA PRÁCTICA SOCIAL DIALÓGICA Y PEDAGÓGICA}

En este trabajo, basados en los fundamentos de la perspectiva histórico-cultural del desarrollo humano, enfocamos la problemática de la mediación pedagógica de la lectura de textos didácticos de ciencias en clases. Argumentamos en favor de la lectura de textos de ciencias, para aprender ciencias, y acerca el papel central que la mediación docente desempeña en este proceso. A partir de datos de una mediación de lectura específica, discutimos las acciones del profesor frente a las contrapalabras de los estudiantes que emergieron durante una lectura compartida. Concluimos que la mediación se constituyó como una práctica social dialógica (por la palabra) y pedagógica (por el otro), que contribuye pare el proceso de comprensión de/acerca de ciencias por los estudiantes, además de resultar en un nuevo texto colectivamente construido por la oferta de contrapalabras.

Palabras clave:Mediación. Lectura. Enseñanza y aprendizaje de las ciencias

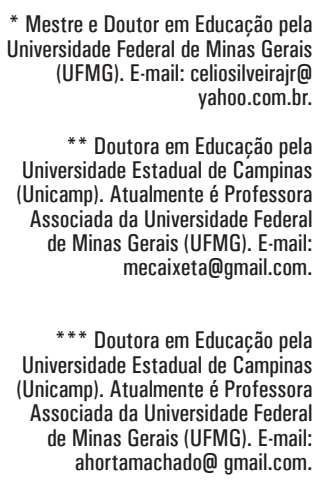

* Mestre e Doutor em Educacão pela Universidade Federal de Minas Gerais (UFMG). E-mail: celiosilveirajr@ yahoo.com.br.

* * Doutora em Educação pela Universidade Estadual de Campinas (Unicamp). Atualmente é Professora Associada da Universidade Federal de Minas Gerais (UFMG). E-mail: mecaixeta@gmail.com.

*** Doutora em Educação pela Universidade Estadual de Campinas (Unicamp). Atualmente é Professora

Associada da Universidade Federal de Minas Gerais (UFMG). E-mail: ahortamachado@gmail.com. 


\section{READING IN SCIENCE CLASSROOM AS A DIALOGICAL AND EDUCATIONAL}

\section{SOCIAL PRACTICE}

Abstract: In this work, based on the fundaments of culturalhistorical perspective of human development, we focus on the problem of pedagogical mediation reading science textbooks in classrooms. We argue in favour of reading science texts to learn science, and about the central role that teaching mediation plays in this process. From data of a specific reading mediation, we discussed teacher's actions in front of student's counter-words that emerged during a shared reading. We conclude that the mediation was created as a dialogical social practice (through words) and pedagogical (for the other), which contributes to the student's process of understanding science and about science, in addition to working a new text collectively built by offered counter-words. Keywords: Mediation. Reading.Teaching and learning of science. 


\section{INTRODUÇÃO}

Geraldi (2007) nos pergunta se ainda é possível falar sobre a leitura, com tantas palavras já em circulação, com tantos discursos já proferidos. Entendemos que sim. Se muito já foi dito no campo da linguagem e da alfabetização, o mesmo não ocorre com a leitura de textos de ciências em salas de aula e suas formas de mediação ${ }^{1}$. Almeida e Sorpreso (2010), referindo-se à área da educação em ciências, descrevem que questões de linguagem e de leitura vêm ocupando um espaço bastante significativo já há longo tempo. De modo exemplificativo, as autoras citam a revisão publicada por Baker em 1991, e o número especial do Journal of Research in Science Teaching de 1994. As próprias autoras, porém, alertam-nos de que é usual que a leitura em si não seja o único, nem mesmo o principal, foco dos estudos. A leitura aparece, frequentemente, associada a outras finalidades. Nesse mesmo sentido, Nigro (2007) aponta que as investigações que abordam a linguagem na Educação em Ciências vêm ganhando papel de destaque. No entanto, o autor julga que a leitura e a escrita vêm recebendo menos atenção, quando comparadas com outros temas: elas parecem ainda ter um espaço marginal. Além disso, em sua opinião, as pesquisas envolvendo leitura na Educação em Ciências concentraram-se nas análises de conteúdos dos textos lidos, nos discursos por eles vinculados e na linguagem de tais textos.

Muitas pesquisas analisam os textos de ciências, mas há carência de trabalhos que estudem os usos de textos didáticos de ciências em sala de aula. Carneiro, Santos e Mól (2005) já apontavam que se conhece muito pouco sobre o cotidiano do livro didático como recurso na sala de aula e sobre concepções de professores e alunos a respeito desse instrumento de ensino. Seria necessário o desenvolvimento de mais pesquisas que se ocupassem dos seus usuários, pois, no Brasil, esses trabalhos ainda seriam muito inexpressivos. Martins (2012), referindo-se à educação em ciências, traça um panorama das investigações sobre os livros didáticos e ratifica um quadro de múltiplos enfoques. Alerta-nos, porém, para o reduzido número de trabalhos a problematizar aspectos relacionados à linguagem e aos usos dos livros na escola. A autora defende que uma forma de complementar os estudos tradicionalmente associados ao livro didático seria tratar do papel da linguagem como obstáculo ou como facilitadora do entendimento. Para ela, abordagens que tomam a linguagem como ação social ajudariam a compreender que as dificuldades dos alunos frente aos textos científicos não se devem somente a dificuldades de entendimento de especificidades gramaticais, léxicas ou sintáticas do texto. Assim, passaríamos de estudos que investigam a legibilidade dos textos e as dificuldades de interpretação segundo uma normatização de sentidos autorizados para estudos das interações entre sujeitos e textos.

Essas interações, porém, tenderiam a ser cada vez menos frequentes dada a constatação de que os livros estão ausentes das salas de aula, como nos diz Paiva (2013). Embora se referindo às obras literárias, entendemos que a análise da autora também é válida para o caso de coleções didáticas, entre elas as de ciências. Para a 
autora, questionava-se anteriormente o fato de os alunos de escolas públicas não terem acesso aos livros. Hoje, os livros chegam às bibliotecas, mas permanecem dentro das caixas. Uma das saídas por ela apontada é a de formação de mediadores de leitura:

\begin{abstract}
As crianças de escola pública só têm acesso aos livros na escola. É a escola que faz a mediação, porque as famílias estão subnutridas de leitura. O resultado do professor como mediador é incontestável, já avançamos muito. Mas sempre é o professor, aquele que faz a diferença na vida do aluno. Precisava ser uma coisa mais consistente, uma ação educacional mais colegiada na escola, no sentido de eleger a formação de leitores não pelo viés da avaliação de proficiência em leitura, mas porque queremos formar cidadãos conscientes, que leem [...] (PAIVA, 2013, p. 8).
\end{abstract}

Entendemos que aprender ciências demanda introduzir o estudante em um novo mundo, em uma nova linguagem. Compartilhamos com Espinoza (2010) a concepção de que é importante ler textos de ciências para aprender ciências. Aprender ciências é aprender também a lidar com o texto escrito que se vale de múltiplas linguagens. O conhecimento científico é validado essencialmente por meio de textos escritos e publicados em eventos e periódicos da área. É um modo de dizer que envolve uma correlação entre evidência e teoria, entre argumentação e persuasão. Ao ler um texto de ciências, o leitor depara-se com certas formas próprias de expressão do pensar. Por isso mesmo, em geral, os textos de ciências mostram-se difíceis para serem compreendidos pelos estudantes sem a mediação do professor. O discurso científico, e mesmo o didático da ciência, é "estranho", contraintuitivo e difícil de ser compreendido (ESPINOZA, 2010). Trata-se de outra linguagem própria à cultura dos cientistas (MORTIMER, 2000). O aprendizado não se faz sem que os estudantes sejam introduzidos nas singularidades desse discurso.

Além disso, ler não é algo simples. Não equivale à decodificação, ao processamento de palavras, ou à manipulação mecanicista de sequências discretas de sentenças (KLEIMAN, 1996). Faz-se necessário pensar a leitura como oferta de contrapalavras do leitor (GERALDI, 2007). Nesta forma de conceber, o texto passa a ser considerado o próprio lugar da interação (KOCH, 2003). Os interlocutores - autor e leitores e professor-mediador, sujeitos ativos da interação- dialogicamente se constroem e são construídos por meio do texto. A compreensão passa a ser entendida como uma complexa atividade interativa de produção de sentidos.

É por isso que a leitura precisa ser ensinada na escola (KLEIMAN, 2007), sem que seja considerada de responsabilidade exclusiva dos professores da língua materna (PAULA; LIMA, 2010). A formação de bons leitores e produtores de texto deveria ser um compromisso e uma responsabilidade de professores de todas as áreas. Como afirmam Silva e Almeida (1998), essa orientação tem sido nutrida no campo da educação em ciências há algumas décadas.A ideia que prevalece, porém, é a de que o estudante alfabetizado sabe ler um texto de ciências, pois já está alfabetizado. Concordamos com Espinoza (2010) quando ela afirma que as situações 
propostas nas salas de aulas de ciências costumam partir do princípio de que os alunos já sabem ler, e que isso seria suficiente para interpretar um texto. Para a autora, normalmente não se pensa em situações de leitura como cenário no qual, ao mesmo tempo em que se ensinam e se aprendem conhecimentos da área, também se ensina e se aprende a ler. Nesse sentido, um rápido exame das assessorias pedagógicas dos livros didáticos de ciências nos permite constatar que, em geral, os autores fornecem pouco ou nenhum suporte para que o professor trabalhe os textos com os estudantes.

É importante os professores de ciências tomarem parte nessa tarefa, engajando-se como mediadores em um projeto de ensino que tenha como referência o aprender a ler de modo a ler para aprender ciências. Concordamos com Geraldi (2010) quando ele diz que a mediação deve ser encarada como um processo em que o professor auxilia o estudante em seu desenvolvimento, em um diálogo com seu futuro. Trabalhar entre o sabido e o potencial é a forma de mediação do professor, que se torna, assim, um coautor dos textos de seus alunos. Passa de um professor leitor-corretor para o de mediador do processo de aprendizagem e, assim, de coenunciador dos textos dos seus alunos. De acordo com esse autor, dizemos que a compreensão do texto didático de ciências também será maior na medida em que o professor como mediador conseguir "ampliar os contextos", fazer emergir "mais vozes" do que aquelas que podem ser imediatamente identificadas nos parágrafos. Explica o mesmo autor que, com isso, não se trata de encontrar a "fonte do dizer", mas para pôr em diálogo outros textos e outras vozes. Cotejar um texto com outros é, de acordo com Geraldi (2012), dar contextos a um texto.

Como a leitura não é ato solitário (SOARES, 2005), e representa a construção de sentidos em um encontro de vozes, ou, segundo Paula e Lima (2010), um encontro de, no mínimo, duas consciências e horizontes conceituais, a do autor e a do leitor, revela-se a importância da mediação intencionalmente planejada do professor antes, durante e após a situação de leitura. O professor, assim, é responsável por criar condições para que seus alunos ingressem nas práticas sociais de leitura como atribuição de sentidos (ESPINOZA, 2010), como uma atividade polissêmica (SILVA; ALMEIDA, 1998; ANDRADE; MARTINS, 2006). Como nos diz Bicalho (2010), é preciso tomar a leitura como objeto de ensino e não se ter improviso em uma aula de leitura:

O professor, ao entrar na sala de aula, precisa saber que tipo de dificuldades os textos podem impor a seu aluno. Ao preparar o texto que será lido em classe, o professor prevê sua atuação como mediador: conhecendo seus alunos e conhecendo o texto a ser lido, poderá propor estratégias de leitura que minimizem as dificuldades. (BICALHO, 2010, p. 94)

É nesse contexto que apresentamos este trabalho, com a intenção de contribuir para o debate na área de educação em ciência sobre a leitura em sala de aula e sobre o papel fundamental que a mediação pedagógica deveria tomar nesse processo. Uma mediação entendida no sentido proposto por Wertsch, Del Río e Alvarez 
(1998), ou seja, como processo que envolve, por um lado, o potencial das ferramentas culturais para modelar a ação, e, por outro, o uso único dessas ferramentas. Aqui, consideramos a mediação pedagógica a partir de um conjunto de instrumentos ou recursos para mediar o processo de ensino, bem como ações intencionais e deliberadas ao usar esses recursos para auxiliar o estudante nos processos de significação do mundo. No sentido mesmo daquele defendido por Reyes (2014), para quem os mediadores de leitura são aquelas pessoas que estendem pontes entre os livros e os leitores, ou seja, que criam as condições para fazer com que seja possível que um livro e um leitor se encontrem.

\section{Questão de investigação e fundamentação teórico-metodológica}

Neste trabalho, portanto, enfocamos a problemática da mediação pedagógica relacionada à leitura compartilhada de textos didáticos de ciências em sala de aula, olhada a partir das ações do professor tanto como intenções previamente planejadas, quanto pela escuta dos estudantes na interação com o texto. Para tanto, nos fundamentamos na perspectiva histórico-cultural do desenvolvimento humano. Essa abordagem concebe o processo de elaboração de conhecimentos como prática social que envolve uma relação entre sujeito e objeto de conhecimento mediada por outro sujeito (SILVA; SCHNETZLER, 2006).

Mas de que conceito de mediação estamos nos apropriando? Daquele que é central na abordagem de Lev Semenovitch Vigotski. De acordo com Wertsch e Smolka (1994), três temas inter-relacionados se estendem por todos os trabalhos de Vigotski: a) a afirmação de que o funcionamento social ou "intermental" dá origem ao funcionamento individual ou "intramental" ; b) a confiança em um método genético ou de desenvolvimento para investigar todos os aspectos do funcionamento mental; c) a afirmação de que os processos humanos psicológicos e sociais são fundamentalmente formados pelos recursos mediacionais que empregam, especialmente a linguagem.

Para Geraldi et al. (2006), Vigotski dá caráter social ao psiquismo humano ao "admitir a possibilidade de o outro mediar, pelo ensino, pelas respostas que é ou que oferece, a aquisição de novos conceitos, novas competências, e com isso mesmo superar etapas de desenvolvimento". Vigotski diferencia funções psíquicas elementares e superiores. As superiores caracterizam o funcionamento psicológico,tipicamente humano, como o pensamento abstrato ou a ação intencional e têm origem nos processos sociais. Conseguimos apreender a qualidade humana dessas funções se compreendemos os instrumentos e os signos que constituem os processos de mediação envolvidos em seu desenvolvimento. Esses meios são sempre instrumentos culturais e históricos, e têm um caráter material que constitui as relações interpessoais das quais participam.

Para Vigotski (2011), o processo de desenvolvimento dos conceitos sistematizados/científicos se produz nas condições reais do processo de ensino, que constitui uma forma de interação sistemática e deliberada do professor com os estudantes. Nessa interação, desenvolvem-se as funções psicológicas superiores 
dos estudantes com a ajuda e participação do professor:

\begin{abstract}
Nessa mediação pedagógica, ele compartilha com os alunos sistemas conceituais instituídos, linguagens, instrumentos, estratégias, procedimentos, atitudes, valores e saberes próprios dessa cultura. Isso tudo envolve os conceitos já dominados pelos alunos, bem como as ações e concepções dos professores/formadores, imbricados nas condições sociais reais de produção daqueles conhecimentos dentro do contexto institucional de escolarização ou de formação profissional (SILVA; SCHNETZLER, 2006, p. 61).
\end{abstract}

O outro participa de forma constitutiva nos processos de mediação de nossa relação com o mundo. A relação do sujeito com o conhecimento não é, portanto, uma relação direta, mas mediada (VIGOTSKI, 1991).

\title{
Procedimentos metodológicos: a construção dos dados
}

Dada a limitação do número de páginas para este artigo, escolhemos analisar uma parte de nossos dados construídos no âmbito da pesquisa de doutoramento do primeiro autor. Ela dá continuidade ao trabalho de dissertação de mestrado (SILVEIRA JR., 2012) e se desenvolve, assim, há mais de quatro anos. Contudo, o leitor poderá cotejar este com outros trabalhos nossos para conhecer o contexto mais ampliado de produção dos dados, bem como outros aspectos das análises que já estão apresentados em pormenores.

Em suma, esta pesquisa busca compreender como o processo de ensino e aprendizagem de conteúdos escolarizados - no caso, ligações químicas desenvolve-se tendo como eixo orientador o livro didático adotado pela escola selecionada ${ }^{3}$. Nosso interesse mais geral foi de responder se faz sentido ensinar modelos de ligações no nível fundamental e que escolhas a fazer em caso positivo. Nossa intenção era a de compreender como o processo de ensino e aprendizagem de ciências, via abordagem das ligações químicas, poderia se desenvolver tendo como fio condutor a leitura mediada de textos didáticos de ciências. Um processo de ensinar-aprender por meio do ler. Aprender a ler e ler para aprender ou ainda ensinar a ler para ler com autonomia e autoria de modo a continuar aprendendo por meio dos textos. Assim, nosso esforço deu-se em duplo sentido: aprender os modelos de ligações químicas, e, por meio da leitura de textos de ligações químicas, aprender a ler textos didáticos de ciências.

Tomamos como desafio ensinar os estudantes a aprenderem por meio de textos intencionalmente planejados, com o objetivo de promover junto a eles uma aprendizagem rica de sentidos, relações e implicações, considerando a perspectiva sócio-histórica já amplamente defendida pela comunidade de educadores em ciências.

Para isso, utilizamos textos da coleção didática "Construindo Consciências" (GRUPO APEC, 2010), com uma turma de estudantes do $9^{\circ}$ ano do ensino fundamental de uma escola pública mineira. A escolha dos textos dessa coleção decorreu de uma análise preliminar, cujos resultados estão apresentados em outro trabalho ${ }^{4}$. Em suma, tanto essa coleção como as outras dez coleções de ciências 
aprovadas pelo Programa Nacional do Livro Didático (PNLD) 2011 foram analisadas com base nos resultados e recomendações de importantes trabalhos que envolveram a temática relacionada ao ensino de ligações químicas. Pretendíamos verificar nas coleções e nos respectivos manuais de orientação pedagógica, destinados aos professores, a complexidade com a qual o tema era tratado, a ocorrência ou não de simplificações que pudessem levar a erros conceituais, e as intenções dos autores em relação ao tema.

Selecionada a coleção didática de referência, o passo seguinte foi procurar uma escola onde a pesquisa pudesse ser realizada. Por óbvio, era necessário que a escola adotasse a coleção escolhida. Igualmente importante era que os estudantes utilizassem efetivamente os livros da coleção, de modo que já os conhecessem e os tivessem utilizados nos anos escolares anteriores. Com isso, já estariam familiarizados com a estrutura, com os textos, e com as atividades propostas por essa coleção. A escola da rede pública estadual na qual o trabalho se desenvolveu cumpria esses requisitos. Foi escolhida entre as dezenove escolas localizadas na região metropolitana de Belo Horizonte, adotantes da coleção, e a única no município de residência do primeiro autor.

$\mathrm{Na}$ escola, expusemos nossa proposta de trabalho à professora da turma de estudantes com os quais trabalhamos. As mediações pedagógicas seriam feitas de forma colaborativa pelos pesquisadores - orientando e suas orientadoras (os aqui autores) - e a professora, o que envolveria o planejamento e implementação das ações de ensino necessárias para o alcance dos propósitos traçados. Vejamos que, assim, vamos de encontro à situação normalmente verificada de ausência de estudos que tenham como foco investigar o funcionamento da leitura e escrita em aulas de ciências, de forma colaborativa com professores. Essa ausência também está presente quando se busca construir espaços de diálogo entre professores e pesquisadores (GIRALDI, 2010) e oportunidades de se refletir sobre o papel da leitura no ensino e na aprendizagem de ciências (ANDRADE; MARTINS, 2006). A professora concordoucom a proposta desde que não houvesse registros por meio de gravações em vídeo, e que as aulas sobre ligações químicas fossem assumidas pelo primeiro autor, o que acatamos. Assim, os registros das mediações se fizeram por meio de gravações em áudio e diversos registros pessoais escritos em caderno de campo, produção escrita dos estudantes, questionários e entrevistas. As referidas aulas foram assumidas pelo orientando conforme acordado.

Nesse contexto, ele passou a assumir, ao mesmo tempo, na pesquisa, os papéis de autor, locutor e personagem. Geraldi $(2012)^{5}$ nos mostra que o pesquisador se relaciona com duas grandes alteridades, dois outros. $\mathrm{O}$ primeiro deles, ou outro 1, é aquele que se encontra no campo, sobre quem falo, e a quem falo como retorno para as formações dos professores e pesquisadores. O segundo, ou outro 2, é o destinatáriolocal (a academia) ou o sobredestinatário (a comunidade de pesquisa), para quem falo. Quando o pesquisador é também sujeito de sua pesquisa, como no nosso caso, ele torna-se também um seu outro, o que acaba por acrescentar mais desafios à sua tarefa. 
Este trabalho, portanto, se enquadra no âmbito da pesquisa narrativa em que se analisa a experiência do vivido (LIMA; GERALDI, C.; GERALDI, J.; 2015) para dela enunciar novas questões de pesquisa e extrair lições para o campo da educação em ciências. A intencionalidade da mediação significou projetar no presente o seu futuro. Promoveu no processo de formação do professor-pesquisador-mediador a oportunidade de planejar, cotejar seu planejamento com os referenciais teóricos, e examinar o ocorrido em sala de aula com um olhar mais profundo e articulado.

Com as ações desenvolvidas, foram construídos os dados de pesquisa. Cinco diferentes textos didáticos sobre ligações químicas foram utilizados (GRUPO APEC, 2010, p. 96-103). Para cada um dos textos, foi elaborado um instrumento específico para condução das aulas orientadas pelas leituras. Totalizaram cerca de 450 minutos de aulas (oito encontros) para as mediações concebidas, gravadas e integralmente transcritas para a construção final dos dados de análise.

Neste artigo, analisamos os dados construídos a partir da leitura compar $\neg$ tilhada de um desses textos. Decidimos colocar em foco o movimento do pro $\neg$ fessor de dar a ler o texto com os alunos e os recursos dos quais se vale a partir das contrapalavras que os alunos trouxeram para o texto e das suas próprias palavras frente aos autores como um projeto próprio de dizer. O que considera $\neg$ mos importante analisar, neste momento, é a mediação docente desenvolvida e os indícios de compreensão dos estudantes. Como nos dizem Freitag, Costa e Mota (1989 apud CARNEIRO; SANTOS; MÓL, 2005), haveria inúmeras possibilidades de um bom professor, usando um mau livro didático, desenvolver um bom ensino e promover um extraordinário aprendizado. Entendemos que o inverso também é verdadeiro. Mesmo se tendo um excelente material didático, pode-se fazer um mau uso dele. Mais uma vez revela-se a importância que a mediação docente desempenha nesse cenário, e justifica-se voltarmos nossa atenção a ela pela centralidade que damos ao professor no processo de ensino e aprendizagem.

\section{A construção da mediação pedagógica em sala de aula}

As leituras dos textos foram mediadas buscando-se sempre estabelecer uma relação dialógica com os estudantes, conectando com estudos que já tinham sido feitos por eles, postergando as "respostas certas" e objetivando instalar, com base nos acontecimentos ali vividos, os propósitos para as leituras vindouras.

As aulas eram iniciadas com a retomada dos resultados da aula anterior e registro no quadro das ideias principais que o texto havia se proposto a tratar. $\mathrm{O}$ objetivo era o de dar um fechamento à aula anterior e construir um propósito para a leitura do texto que se faria na sequência. Espinoza (2006) defende que a instalação de propósitos de leitura, em etapa anterior ao trabalho com os textos, faz com que os estudantes tenham perguntas genuinas ou próprias sobre o conteúdo que se desenvolverá. Por consequência, esperávamos promover uma escuta e uma leitura produtivas, adjetivadas e circunstanciadas como sendo aquelas que, segundo Geraldi (2013, p. 17), 
[...]não repetem as palavras do locutor/autor, mas constroem uma compreensão e a elas podem acrescentar uma interpretação, tomando esta como a compreensão associada a uma criação (crítica ou não, mas que leva adiante e para frente aquilo que se compreendeu).

Uma característica central da mediação pedagógica proposta consistia em buscar no texto, com os estudantes, pistas, marcas ou indícios de relacionamento com as ideias centrais em discussão (GINZBURG, 1989). A intenção era avançar sempre mais no sentido de dar determinado acabamento às questões tratadas pelos textos e os variados sentidos que vieram sendo atribuídos/negociados a cada aula. O que significando, portanto, que o acabamento não estava relacionado ao fechamento de sentidos, mas à inscrição destes em marcos conceituais mais amplos pela recursividade. Tal acabamento era dado problematizando os diversos sentidos e destacando aqueles que mais se aproximavam dos projetos de dizer dos autores dos textos de referência e do professor-pesquisador. Sentidos estes cientificamente aceitos na atualidade, além de indicar a demanda de outras leituras, outros textos. Ao final das aulas, era solicitada a produção de um texto pelos estudantes. A intenção era a de que eles sintetizassem o que havia sido lido, considerando os seguintes aspectos: a) Que questão o texto lido se propunha a discutir? b) Que resposta o texto lido fornecia a essa questão?

Outra característica dessa mediação pedagógica foi a ênfase dada à relação modelo-propriedades ${ }^{6}$, destaque que vai ao encontro do que defende Paula (2004) quanto à centralidade dos modelos no processo de tornar mais complexo o nosso conhecimento sobre o significado de princípios e teorias. A opção por estabelecer essa tensão entre propriedades e modelos foi de nos afastarmos das tradicionais classificações das substâncias a partir dos tipos de ligações formadas como um fim em si mesmas e com foco na memorização, entendido como repetição e não compreensão.

Também, a leitura do texto não se resumiu aos aspectos verbais do texto, voltando-se, da mesma forma, aos aspectos imagéticos. O objetivo era de queos estudantes aprendessem a atribuir sentidos às imagens comoum texto, isto é, como complementaridade do discurso verbal em vez de meras ilustrações ou curiosidades. A partir da mediação, buscou-se também antecipar as dificuldades dos estudantes e assinalar caminhos para a aprendizagem, no sentido que defende a perspectiva histórico-cultural. Para Freitas (2010), o professor é aquele que pode funcionar intervindo e mediando a relação do aluno com o conhecimento.

\section{Análise da mediação pedagógica da leitura de um texto específico}

O texto "As ligações entre os átomos de um metal" (GRUPO APEC, 2010, p. 98) aborda a questão da forma como os átomos devem estar ligados em um metal. Faz-se a partir da análise das propriedades dos metais e conclui que a ligação metálica tem, como modelo, átomos carregados positivamente, unidos por uma grandequantidade de elétrons livres que se movimentam entre esses átomos 
do metal. Considerando-se o encadeamento dos textos propostos para apresentar os tipos de ligações e materiais, uma grande ideia a seguir era a da existência de cargas em movimento para explicar a condutividade elétrica de metais e de compostos iônicos fundidos e em solução. Em nosso planejamento, tal texto era o segundo dos cinco selecionados para tratarmos das ligações químicas, e sucedia a leitura e desenvolvimento do experimento previsto no texto Testando a condutividade elétrica de alguns materiais (GRUPO APEC, 2010, p. 97). A leitura do texto As ligacoões entre os átomos de um metal envolveu os seguintes procedimentos: 1) A retomada com os estudantes dos resultados dos experimentos da aula anterior sobre a condutividade elétrica dos materiais; 2) A leitura da parte inicial do texto; 3) A retomada da noção de modelos; 4) A leitura do restante do texto; 5) O destaque da ideia principal de cada parágrafo do texto; 6) A socialização das ideias principais do texto; 7)A identificação de ideias-chave dos parágrafos do texto por meio da associação a temas predefinidos; 8) A produção de um texto de síntese.

Vejamos que a dinâmica de ler um texto, parágrafo por parágrafo, interrompendo e explicando é um dos modos mais recorrentes e intuitivos dos professores realizarem leitura de texto didático em classe. Contudo, consideramos importante analisar as possibilidades e limites dessa dinâmica, aqui tida como um dos recursos mediacionais de compreensão. Dos procedimentos descritos acima, temos a utilização de recursos que estão para além da mera vocalização dos parágrafos do texto. A retomada com os estudantes dos resultados dos experimentos da aula anterior não estava prevista no texto que ora seria lido. Começar pelo experimento foi um movimento intencionalmente planejado, uma vez que as discussões suscitadas durante a realização e discussão desse experimento - ou seja, com a "leitura do texto experimento" - constituíam a criação de propósitos para o estudo dos textos que o sucedeu. O sentido de um texto está sempre em diálogo com outros textos e, nesse, caso, antecipou a necessidade e o modo de abordagem dos últimos.

Da mesma forma, a retomada da noção de modelos também não está no texto, mas é trazido a ele, em um movimento de coautoria, complementação, e preenchimento de lacunas do texto apresentado aos estudantes. Nesse sentido, o professor, para ler o texto, não só verbaliza o dito, mas preenche os vazios para aqueles sujeitos que o leem naquele momento. Na direção apontada por Silva e Almeida (2005), verifica-se que as interações nas aulas estavam muito além dos textos lidos, embora sempre a eles relacionadas. Esse movimento representa uma leitura que se produz pelo hipertexto que vai sendo construído pelo compartilhamento com o professor e pela recorrência a outras fontes. Ele não só lê o texto como o "reescreve" a partir do que sabe dos alunos (o que já estudaram, dificuldades mais frequentes indicadas pelas pesquisas na área ou pela experiência como professor, etc.). Assim, a leitura é também uma nova escrita, de onde emerge um outro texto em produção por efeito do que as contrapalavras produzem em nós. O modo como mediamos a leitura é a resposta ao que fazemos - ou não - com as contrapalavras dos estudantes e dos autores que povoam o nosso universo de leitor.

Também, o destaque da ideia principal de cada parágrafo é outro recurso a cons- 
tituir esse processo de mediação de leitura. Uma ideia principal ou essencial na compreensão do texto não resulta, neste nosso caso, na identificação de frase ou parágrafo em que a resposta desejada pode ser localizada. A leitura do restante do texto pressupõe a necessidade da compreensão do todo do texto de modo a ser capaz de perguntar/responder qual é a moral daquela história para o autor e qual é a moral para o leitor que não precisa, necessariamente, coincidir ou restringir uma à outra. Prova disso é a confusão, muitas vezes, causada entre autor, professor e estudantes quando gabaritos de testes são apresentados como respostas ao "o que o autor queria dizer" ou qual seria a ideia principal. O movimento aqui do professor com os estudantes é o de correlacionar as partes com o todo, análise/síntese ou decomposição e recomposição para além da soma das partes. Indiciar o que transcende. Ainda, a produção de um texto de sintese sinaliza a intenção de se ter uma leitura, como criação ou não, mas que leve adiante e para frente aquilo que se aprendeu. Uma síntese não como repetição das palavras do autor/locutor, mas como coautoria do texto lido.

Voltando-nos propriamente para as interações ocorridas durante a mediação pedagógica relacionada à leitura desse texto, destacamos aqui trechos transcritos que correspondem à parte dos turnos de fala apenas do professor ${ }^{7}$.

1.Olha só, gente. É esse texto aqui. Para que a gente vai ler esse texto aqui? Vamos retomar os resultados do experimento que a gente fez na $2^{\mathrm{a}}$ feira.Naquele experimento, nós vimos que alguns materiais conduzem carga elétrica e outras, não. Quais são os que conduzem? 2.Sal! Então, vocês estão me falando que o sal com água conduz. Moeda. Sal puro, não! Ok, ele viu, e nós vamos ter que arrumar um modelo para explicar o que ele viu 8. Depois. Olha, só: e os metais? Os metais conduzem? Esse texto aqui vai começar a nos explicar o que é que ocorre com os metais para eles conduzirem, e os textos seguintes vão dizer para os outros materiais: porque uns conduzem e outros não conduzem. Eu queria que prestassem atenção na leitura que vamos fazer. Então, vamos lá, olha! [Leio o título do texto9 ]: "As ligações entre os átomos de um metal." O [que] será que esse texto quer nos dizer? Qual a pergunta desse texto? Qual a resposta que a gente vai obter com esse texto? Então, vamos começar a ler isso. Olha só o primeiro parágrafo. São sete parágrafos, né?E mais uma figura com uma legenda. Então, estou no 1o.[Leio a primeira frase desse parágrafo. Pauso para comentar]. Então, para a gente bolar um modelo para explicar como determinado material funciona, a gente tem que levar em consideração as propriedades desse material. Aí, a gente começa a falar dos metais. Olha só. [Leio a segunda frase. Pauso para comentar]. Em geral, os metais são dúcteis, quer dizer, eles formam fios. É por isso que a gente tem fios de? [Pergunto aos estudantes].

Já destes primeiros turnos transcritos, especialmente a partir das partes grifadas, pode-se verificar a diferença que há entre ler para os estudantes (ou com eles) para ensinar um assunto, e ensinar a ler para aprender a ler e aprender um assunto. A retomada das questões suscitadas com o experimento e a sua vinculação à finalidade do texto, que ora se apresentava, e dos que se seguiriam possibilitava a criação das condições para a emergência de perguntas genuínas com as quais os estudantes poderiam aportar ao texto. Como nos diz Espinoza (2010), devem existir condições didáticas que facilitem a apropriação pelos estudantes dos conteúdos 
tratados. A autora refere-se à importância de se criar um propósito para a leitura e de se conceber intervenções por parte do professor que ajudem a interpretar o texto e, ao mesmo tempo, capacitar os alunos para assumir sua responsabilidade como leitores. Tratar-se-ia de criar um contrato didático que permitisse aos alunos assumirem a responsabilidade da leitura, de modo a saberem por que leem, a desenvolverem uma maneira própria de ler, a encontrarem formas de corroborar suas interpretações - algo que favoreça a formação de leitores críticos. Esse contrato didático é que objetivamos firmar desde as nossas primeiras intervenções, sem nos furtarmos também, da necessária relação a ser estabelecida entre propriedades dos materiais e os seus modelos explicativos.

3.De cobre, por exemplo, né? [Continuo a leitura. Pauso para comentar]. São maleáveis, formam lâminas. Vocês já viram essas chapas de ferro, chapas de aço? Vocês já viram papel-alumínio? Aquilo é uma lâmina de alumínio de uma espessura muito pequena. Então, com os metais, a gente consegue fazer fios, chapas, lâminas. [Continuo a leitura. Pauso para comentar]. Os metais têm alta condutividade elétrica. A gente viu isso no experimento? [Volto a ler]. E apresentam um brilho que lhes é característico quando são polidos. Então, as panelas, quando são areadas, elas apresentam brilho. [Volto a ler]. E, além disso, os metais são bons condutores de calor, né? De energia, de calor. Vamos passar para o segundo parágrafo aí. [Leio a primeira frase. Pauso]. Quer dizer, os metais apresentam uma série de propriedades, e a gente tem que bolar um modelo para explicar isso. [Volto a ler. Pauso]. Gente, eu acompanhei uma aula aqui de vocês com a Professora [digo o nome] em que foi tratado de modelos. Alguém pode me dizer o que entende por modelo?

Sabemos que não há um momento determinado para a realização de um experimento. Em nosso caso, entendeu-se que ele deveria inaugurar a leitura dos textos sobre ligações químicas, pelos motivos já descritos: ter o experimento como motivação para a leitura dos textos vindouros, no sentido defendido por Espinoza, Casamajor e Pitton (2009): a partir de uma situação criada pelo docente, transformar-se para o aluno em um objetivo próprio, ou seja, ele "querer ler" porque "necessita saber".

Com a opção de realizarmos primeiro o experimento, alterou-se a ordem na qual os textos estavam apresentados na coleção didática, o que é mais uma evidência da coautoria do professor nessa história, nessa narrativa cuja temporalidade elenca novos elementos em termos de construção de uma moral pela mobilização de recursos mediacionais da leitura. No fragmento das interações apresentado no número 3, vemos que a relação entre modelos e propriedades é novamente assinalada, bem como dá-se início à discussão sobre a construção dos modelos. Como nos episódios relatados por Espinoza, Casamajor e Pitton (2009), dessa maneira o docente propõe refletir sobre como se pode chegar a pensar sobre coisas que não se veem, o que era importante para o nosso objetivo de também se ensinar sobre ciências que pensa o mundo que não vemos ou que cria modelos para explicar o mundo.

Nessa retomada dos resultados do experimento, há de se verificar também a utilização de mais um recurso de leitura. Em vez de glossário, definições, 
etc. o que é "ser maleável” aparece num processo crescent de significação como "poder ser transformado em lâminas" e, em seguida, pela apresentação de um exemplo disso no cotidiano, que é o do papel- alumínio. Outro adensamento do sentido de lâmina que, sendo bem fina, parece um papel. Introduz-se nova ideia: não só lâmina, fios. Por que dos fios? Para puxar uma das ideias matriciais, condutividade e carga. Condutividade térmica e elétrica e a ideia de que metais podem ser identi- ficados pelo brilho característico deles.

\begin{abstract}
4.[Alguém pode me dizer o que entende por modelo?] É uma forma de energia?!
5. Retomando respostas dos estudantes] Então, você está me dizendo que é uma forma de expressar energia? É uma espécie de desenho 3D? O modelo é uma forma de explicar a teoria? Olha só: eu queria que vocês dessem um pulo lá na página 60 do livro $\frac{10}{}$. A gente vai ler as três primeiras linhas dessa página 60. É o início aí. [Leio a primeira frase. Pauso]. Então, olha só: modelo é alguma coisa que a gente elabora para tentar explicar a realidade. Não é algo acabado, não é algo definido. Tá sempre em constante alteração, se ele não é capaz de explicar a realidade. Então, eu queria contar para vocês - não sei se a Professora [digo o nome] já contou para vocês - o modelo que foi criado, imaginado, para : aquela que a gente colocava uma moeda e saía uma latinha. Já viram essas máquinas?
\end{abstract}

Aqui, vemos que o professor acolhe as contrapalavras dos estudantes, promovendo um desvio de percurso e convidando-os a visitar uma outra página para ler um outro texto que se torna parte do que está em discussão. Era preciso que entendessem o jogo entre modelo e realidade, invenção e compromisso para compreenderem tal relação ou correspondência no texto em estudo. Esse retorno a um texto anterior não estava previsto ali, mas considerado como subtexto já compreendido pelos estudantes e recursivamente retomado em um nível de complexidade maior. As contrapalavras dos estudantes criam um momento de suspensão da leitura desse texto para preencher uma lacuna flagrada como tal pelo professor e não pelos autores, pelo menos na materialidade daquele texto. Olhar para o que o professor faz com as contrapalavras suscitadas pelos textos de ciências é importante, pois, em geral, nossas práticas envolvem mais a explicação - a palavra de um - do que a compreensão como ponte entre dois ou mais. Na explicação, os sentidos que circulam entre os sujeitos são fechados em torno do que se quer definir, ou seja, damos fim (de-finimos o) ao processo de circulação. O universo das dúvidas, dos modelos, das concepções é reduzido à concepção da ciência. Mediar pressupõe ler o dito e o não dito. O não dito nesse caso é preenchido com uma pausa longa ainda que anunciada pelo professor como leitura de apenas três linhas, com outro texto, porque o professor sabe que o que está sendo ensinado é uma teoria de ligações que resulta da articulação entre modelos e propriedades.

6.Então, tem um professor de química, já idoso, viaja o Brasil inteiro dando palestras. Ele se chama Attico Chassot, e ele, para explicar essa questão de modelo, ele contou uma historinha que eu vou adaptar aqui. [...] 11

A referência e história também não estavam no texto. O professor preenche com 
o que sabe, dando humanidade ao texto como produção de outro colega.

7.Pois é! Eu deslacro depois de vários meses, ligo a máquina, coloco uma moeda. Passa um tempinho, vem uma latinha. Como é que explico esse modelo? É possível ainda esse modelo ser viável?

8.Então, me explica por que. São vários meses. O anãozinho é uma pessoa, né?

9.Se ele morreu, como é que a latinha veio?[Retomando os comentários].

10.Eu lacrei a máquina toda durante vários meses. Desliguei. Depois eu deslacrei, liguei a máquina. Quando eu coloquei uma moeda, a latinha veio. Eu quero ver se esse modelo é viável, pensando que tem um anãozinho ali dentro.

11. Mas, como é que você iria conseguir sobreviver dentro de uma máquina fechada? [Retomando os comentários].

12.Exatamente. Mas, ele teria que tomar todo o refrigerante.

13.Não, a máquina estava lacrada. Não entrava nem saía nada. Então, gente, isso prova que esse modelo não serve. Eu teria que inventar um outro modelo, bolar um outro modelo. 14.Oi? O anão não existia. A gente tem que pensar em outro modelo.

15.É. Você pode criar um modelo e imaginar que tem um robozinho ali dentro. Mas aí, é outra história.

Aqui, o professor implica os estudantes na nova narrativa, busca suas contrapalavras nesse processo de leitura. Como nos diz Geraldi (2007), um leitor/ ouvinte que não oferece às palavras lidas/ouvidas as suas contrapalavras, recusa a experiência da leitura. É preciso vir carregado de palavras para o diálogo com o texto. Mais simples, talvez, seria a explicação direta sendo dada pelo professor. Mas, nos mostra Bakhtin (2003), para a compreensão, necessitamos de mais de uma consciência. Na explicação, existe apenas uma consciência, um sujeito.

16. Bom, esse parêntesis todo é porque a gente vai tratar de modelo para ligaç̃es químicas. Modelo para ligação metálica. Então, esse modelo vai existir enquanto responder à realidade. À medida que o teste não for funcionando para esse modelo, ele tem que ser substituído. [Voltando ao texto da p.98].Então, vamos lá para o terceiro parágrafo. [Leio todo o parágrafo. Pauso]. Então, o metal vai ser um bom condutor porque tem cargas elétricas que podem se mover de um lugar a outro. Vamos ler esse $4^{\circ}$ parágrafo, que é maior. [Leio a $1^{a} \mathrm{e}$ $2^{a}$ frases. Pauso].Eu queria que vocês olhassem essa legenda, essa ilustração. Então, o que tá dizendo aqui? Eu tenho átomos de prata, né? O símbolo Ag, prata. Que tem o sinalzinho + (mais) aqui. Positivo. E tenho aqui representados de vermelho... Essa não é a cor dos elétrons, tá? É só ilustrativo. Que se movem entre os átomos que são carregados positivamente. Então, vamos continuar a leitura. [Leio o restante do parágrafo. Pauso] Então, eu tinha átomos neutros. Que elétrons e prótons eram... Cargas negativas e positivas eram as mesmas. E, depois, esse núcleo fica positivo, e esses elétrons ficam circulando entre eles. $\mathrm{O} \underline{5^{\circ}}$ parágrafo. Como é que chamam os átomos carregados positivamente? [Espero respostas dos estudantes]. Não? Qual o nome que se dá aos átomos que são carregados positivamente?

Neste momento, o professor explica a razão da longa pausa, do parêntesis realizado. Isso não está em nenhum dos dois textos, pelo que se conclui que os autores consideraram sabidos e atualizados na memória dos estudantes, o que não era verdade. Quem escreve não preenche tudo quanto é lacuna que vai aparecendo. Mediar implica em ajudar a preencher aquilo que há na situação de interação do 
leitor com o texto. O professor flagra como obstáculo ou necessidade de para um futuro que já vislumbra e quer antecipar. De novo é a mediação do professor que ajuda os estudantes a continuar lendo de forma mais enriquecida o texto que está lá no livro didático. Eles podem agora acrescentar uma interpretação ao modelo para ligação metálica como a relação entre modelo e realidade, e avaliar a sua validade. Além disso, o professor localiza os estudantes no texto, o onde estamos. Também não salta a imagem intercalada com o texto verbal. Detém-se nela e ajuda os estudantes a interpretá-la, isto é, a construir um texto que articula e completa, mutuamente, essas duas linguagens. Como nos diz Piccinini (2012), ao tratar das imagens no ensino de ciências, elas podem sensibilizar, convencer e persuadir, mas a função de texto como sentido em produção, que determinadas imagens apresentam, demanda auxiliar o estudante na sua leitura e, portanto, precisa ser tratada como algo que deve ser aprendido a ler na escola. Aprender a ler imagens dos textos é central para a construção de uma visão situada e crítica da realidade e do conhecimento. $E$ a nossa mediação da leitura continua. Aqui, a ideia de cargas é fundamental para a compreensão das ligações, das forças eletrostáticas.

17. Prótons! E os que são carregados negativamente?

18. Elétrons! É isso que vai dizer esse $5^{\circ}$ parágrafo. [Leio o parágrafo]. Então, eu tenho cátions e ânions. $\mathrm{O} 6^{\circ}$ parágrafo. $\mathrm{O} 6^{\circ}$ parágrafo vai dizer então qual é o modelo proposto para a ligação metálica. É importante este parágrafo. Olha só. [Leio o parágrafo]. O último parágrafo. Para a gente passar para a nossa atividade. [Leio o parágrafo]. O que que a gente pode concluir? Que as propriedades que os metais apresentam são devidas a quê? [Espero respostas. Estudante pede que eu fale de novo a questão]. Falo! A gente tá vendo... A gente tá tentando criar um modelo para ligação metálica, ligação entre átomos do metal. Os metais apresentam uma série de características. Condutividade elétrica, maleabilidade, ductilidade... Isso tudo pode ser explicado por que fato? Qual é a característica que os metais apresentam que pode explicar essas características outras que eu acabei de falar? É o que tá dito neste último parágrafo. [Releio o final do parágrafo]. "Estão relacionadas à facilidade de movimento dos elétrons livres que os metais apresentam".

O que a gente pode concluir? É um desafio proposto aos estudantes para a produção de um texto pessoal para além da mera repetição. No sentido de uma leitura produtiva, aquela que, como vimos, envolve palavras próprias. Como defendem Paula e Lima (2011), é importante instaurar práticas de leitura nas aulas de ciências de modo a provocar os sujeitos leitores e evocar neles um projeto de dizer. Mesmo que os estudantes não deem conta desse processo completamente, o desafio está posto. Ao final, o professor localiza no texto para eles o modo como os autores concluem. De qualquer forma, esses sujeitos saem modificados desse processo. Como nos diz Geraldi (1996), na experiência de leitura, o leitor sai modificado ou porque adere aos pontos de vista com que compreende o mundo, ou porque modifica tais pontos de vista em face do diálogo mantido através do texto com os seus autores.

A mediação pedagógica da leitura demandou muito esforço ou trabalho 
semiótico por parte do professor e dos estudantes. A leitura do texto de uma página durou cerca de 45 minutos. Outros 45 minutos, aproximadamente, foram dedicados à avaliação da leitura sem considerar a aula experimental que consistiu na criação do propósito para ler.

Ao final, os estudantes realizaram algumas atividades que envolviam outras estratégias de leitura para relerem o texto e encontrar respostas às questões. Em outras palavras, buscavam contribuir para o processo de aprender a ler textos didáticos de ciências de modo a ler para aprender ciências. Esforço que pode ser percebido por meio das ações desenvolvidas pelo professor, entre outras: retomar, em cada início de aula, o que foi tratado nas aulas anteriores ou mesmo reestabelecer nexos de um parágrafo para outro ou ainda entre os diversos textos mobilizados; negociar os sentidos focando a atenção deles em determinadas frases ou enunciados dos autores, trazendo exemplos e conceitos ausentes ou novos, fazendo perguntas, usando sinônimos, etc.; produzir sínteses provisórias em diferentes momentos e explicitar a ideia final com a qual os autores resumem a narrativa ou explicitam a moral do texto para eles; e tomar a mediação da leitura como uma necessidade de formar sujeitos leitores dos textos didáticos de ciências com suas múltiplas linguagens.

Um dos propósitos foi ensinar a ler- e não ler com eles- para explicar modelos no caso de não darem conta de entender o texto sozinhos. Não foi um usar a leitura apenas para ensinar ligações, mas, por meio da leitura de textos sobre ligações químicas, aprender a ler textos dessa natureza e aprender sobre o assunto. Caso o propósito se reduzisse ao ensino de ligações, poderíamos ter feito uma aula dialogada na qual o texto didático não tivesse o protagonismo que teve. A leitura dele poderia ainda ter sido indicada para casa ou de outro modo.

A aula se organizou em torno dos processos de significação do texto, numa ruptura com a regra, a rotina da classe. Assim, entendemos não ter reproduzido os procedimentos que normalmente ocorrem em sala de aula quando dizemos: "vamos ler, cada um lê um parágrafo e para esclarecimento de dúvidas; leiam o texto da página tal e respondam os exercícios para corrigirmos; leiam em casa o texto da aula seguinte para trazerem suas dúvidas" e daí por diante.

A relação modelo-propriedades, fundamental em nossos propósitos de ensino, e que já vinha sendo tratada desde o estudo do primeiro texto, foi sistematicamente retomada procurando atingir os objetivos propostos pelos autores, os de ensinar ligações no $9^{\circ}$ ano de um modo diferente do que se tem em outras coleções. A atenção recaía sobre a ideia de que para explicar propriedades diferentes, fazemos modelos diferentes. Por fim, foi feita uma proposta de um modelo para as ligações entre os átomos de um metal. Ensinar a ler o texto representou pensar na relação modelo de ligação metálica com suas cargas em movimento e nas propriedades dos metais como condutividade elétrica. Essa relação foi tensionada o tempo todo, como pudemos ver/analisar.

Tensão essa que encontramos adicionalmente nos turnos que se referiram aos modelos para a máquina de refrigerantes. Esses turnos, também, apontam para 
mais uma característica da mediação pedagógica em questão: a recorrência a outro texto - a criação de um hipertexto - em um projeto de ensino que cria os nexos necessários. Aqui, a mediação buscou antecipar as dificuldades e assinalar caminhos para a aprendizagem. A partir de um texto, foi se construindo um outro texto pela mediação, o que resultou num hipertexto como se vê materializado com os recursos da internet e das variadas ferramentas das tecnologias da informação e comunicação. O professor leu com os estudantes muitos outros textos. Na mediação, vamos encontrando lacunas, vazios, subentendidos, e vamos pela mediação buscando outros textos para compor o projeto de elaborar significados com o texto e sobre o texto. Consideramos essa leitura extremamente dialógica, pois faz saltos no tempo e no espaço. Isso vai tornando o processo de aquisição das ferramentas de leitura mais rico. Os estudantes aprendem que ler implica ir a outros textos, em um processo de intertextualidade, que permite checar ideias, complementar informações, promover novas relações, complexificar a compreensão que o texto original não seria capaz de dar conta sozinho. Esse modo de pensar cria uma tensão na consciência dos alunos, pois os desloca em termos de pensamento e espacialidade. Exige um disciplinamento intelectual para correlacionar com outras informações, estabelecer nexos de implicação, encontrar contradições ou complementaridades. Isso aumenta a nossa capacidade de fazer mais inter-relações, de elaborar questões, de concluir a partir de um número maior de dados e informações. Tudo isso já está muito presente na vida dos estudantes possibilitado pela internet.

Outra característica da mediação pedagógica analisada é a de que a leitura do texto não se resumiu aos aspectos verbais, mas também se voltou aos imagéticos, como vimos. De acordo com Martins (2012), o texto do livro didático é organizado a partir de uma diversidade de linguagens: verbal (texto escrito), matemática (equações, gráficos, notações), imagética (desenhos, fotografias, mapas, diagramas). Essa característica do texto impõe demandas às práticas de leitura de professores e estudantes, que precisam lidar com a complexidade de um texto multimodal.

\section{CONSIDERACְ̃̃ES FINAIS}

$\mathrm{Na}$ mediação de leitura relatada, entendemos que fomos ao encontro do que defende a perspectiva histórico-cultural do desenvolvimento humano, e, em particular, do sentido que Vigotski dava para a mediação: as atividades com signos e o fenômeno de interação entre sujeitos. Procuramos tornar o processo de aprendizagem uma prática social dialógica (mediada pela palavra) e pedagógica (mediada pelo outro), como nos diz Smolka (2000). Essas formas de mediação marcam a atividade mental do indivíduo no sentido de que seus modos de agir e de pensar estão profundamente enraizados no contexto e impregnados na/da dinâmica social. Entendemos que também contribuímos para o processo de ensino e aprendizagem no qual os estudantes estiveram envolvidos, favorecendo a 
elaboração conceitual, a construção de modelos e teorias de ligações e a experiência com a leitura do texto didático de ciências. Baseando-nos no que dizem Ricon e Almeida (1991), esperamos que essa experiência tenha contribuído para que o estudante continue mais tarde, já fora da escola, a buscar pela leitura informações necessárias à sua vida, a checar notícias, a estudar, a se aprofundar num tema, ou, simplesmente, a se dedicar à leitura pelo prazer de ler. De acordo com Freitas (2010), para Vigotski há aprendizagem quando se internaliza o que foi vivenciado na relação com o outro. A internalização acontece a partir das significações construídas no processo interativo às quais o sujeito confere um sentido pessoal. Não significa, necessariamente, uma apropriação de conteúdos no sentido restrito do termo, como produtos acabados, definidos, mas de um processo oportunizado pelas vozes que circularam e pelas relações dialógicas entre elas.

O episódio analisado destaca a importância da mediação pedagógica intencionalmente planejada e construída a partir da compreensão dos aspectos teóricos explicitados de forma a dar destaque aos processos de significação na leitura de textos de ciências. O que foi feito? Uma movimentação do professor em torno do texto para discutir o que são modelos; como a ciência produz modelos; que compromissos epistemológicos existem entre modelos e realidade; como deve ser o modelo para um metal e, acima de tudo, ensinar a ler textos de ciências para aprender ciências. Oportunizamos aos estudantes uma leitura compartilhada e com o uso de diversas estratégias para torná-la produtiva em termos da dupla aprendizagem: modelos científicos e textos didáticos de ciências. E por que torná-la produtiva? A pesquisa, o pesquisador e seu outro como ato responsável, um experimento responsivo:

\footnotetext{
Uma teoria precisa entrar em comunhão não com construções teóricas e vida imaginada, mas com o evento realmente existente do ser moral - com a razão prática, e isso é responsavelmente completado por quem quer que se conheça, na medida em que o ato de cognição esteja incluído como minha ação, com todo o seu conteúdo, na unidade da minha responsabilidade, na qual e pela qual eu realmente vivo - executo ações. (BAKHTIN, 2010, p. 58).
}

E como o professor executou as suas ações? Por meio de uma leitura teotônica (ordenada parágrafo a parágrafo); pela criação de propósito e explicitação do propósito nos dois momentos (experimento e da leitura: épara isso e foi para isso); pelas recorrentes digressões acompanhadas pela introdução de dados de memória (a professora de vocês...; vamos dar um pulo na página 60; vejam a figura); preenchendo lacunas entre o texto e o que os estudantes dão pistas de não saberem do que se trata; garantindo o espaço para os dizeres dos estudantes, ao mesmo tempo em que assumia o protagonismo docente de mediador nessa relação de ensino. Como nos dizem Zimmermann e Silva (2007), os diferentes modos de leitura estabelecem ou podem estabelecer diferentes relações entre o professor e o estudante, bem como entre o professor, o estudante e o texto. E estas dependem das condições de pro- 
dução, ou seja, do contexto e das posições relativas dos sujeitos.

O que temos aprendido é que a escola não tem tempo para esse tipo de processo, lento e trabalhoso. Explicar é mais rápido e mais fácil, e a leitura em Educação em Ciências parece não estar presente no dia a dia dos professores (NIGRO, 2007). A avaliação da aprendizagem centra-se nos produtos acabados e memorizados para serem repetidos tal qual a informação inscrita no texto e, por isso, não temos "tempo a perder" com processos demorados e difíceis de serem medidos em termos de aquisições humanas. Aprender a ler um texto didático de ciências é uma tarefa a longo prazo, contínua, persistente e diversificada em termos de estratégias de leituras. Concordamos com Reyes (2014) quando ela diz que o trabalho do mediador de leitura não é fácil de ser reduzido a um manual de funções. Seu ofício é ler de muitas formas possíveis: em primeiro lugar, para si mesmo; em segundo lugar, criando rituais, momentos e atmosferas propícias para facilitar os encontros entre os textos e os leitores; por fim, lendo os seus leitores, antevendo suas possíveis dificuldades com o tipo de texto e conteúdo disponibilizados para esse encontro. Tendo consciência dessas particularidades a envolver a mediação de leitura, o professor estará em melhores condições para realizar suas escolhas: do conteúdo a abordar, do texto a selecionar, dos demais recursos a utilizar, e até mesmo da decisão de ler ou não ler, de como e quando ler.

Nesse sentido, a mediação da leitura é mais do que a mera vocalização do texto parágrafo a parágrafo com os estudantes, ou realizada por um dos sujeitos e acompanhada silenciosamente pelos demais. Ainda que ela se reduzisse a esse procedimento, o que importam, como nos dizem Espinoza, Casamajor e Pitton (2009), são as condições sob as quais o docente apresenta essa leitura para que possa ser uma ferramenta que os alunos usem para problematizar suas ideias, modificar suas representações, ampliar seu marco de referência e, assim, explicar os fenômenos da natureza utilizando a linguagem da ciência. Trata-se de gerar condições para que, ao ler, os estudantes possam se apropriar das ideias da ciência e que isto lhes permita explicar fenômenos, ao mesmo tempo em que aprendem a ler textos da área para seguirem o próprio caminho desvencilhando-se dos professores.

\section{NOTAS}

${ }^{1}$ Dada a restrição de espaço, não foi nosso objetivo aqui fazer uma revisão minuciosa dos trabalhos dedicados ao tema. Limitamo-nos a apresentar algumas referências que vão ao encontro do entendimento que expressamos. Para uma revisão mais detalhada, veja Silveira Jr. (2015). 2"Todas as funções no desenvolvimento da criança aparecem duas vezes: primeiro, no nível social, e, depois, no nível individual: primeiro entre pessoas (interpsicológica), e, depois, no interior da criança (intrapsicológica)" (VIGOTSKI, 1991).

${ }^{3}$ Sobre as dificuldades associadas ao ensino e à aprendizagem do tema "ligações químicas" e sobre uma proposta de análise de livros didáticos sobre esse conteúdo, veja Silveira Jr., Lima e Machado(2012). 
${ }^{4}$ Para as justificativas das escolhas da escola e da coleção didática, veja Silveira Jr. (2015).

${ }^{5} \mathrm{~A}$ partir das falas do prof. João Wanderlei Geraldi durante a disciplina Conhecimento, ensino e pesquisa, ministrada na Faculdade de Educação da Unicamp em março de 2012.

${ }^{6} \mathrm{Em}$ nosso planejamento, ler os textos significava aprender a relação entre modelos e propriedades: um projeto de ensino dos autores da coleção didática que foi tomado para si pelo professor.Para saber mais sobre a importância que atribuímos a essa relação, veja Silveira Jr.(2015).

${ }^{7}$ Cerca de 90 minutos foram dedicados à leitura e à avaliação da leitura desse texto. As transcrições apresentadas referem-se à parte da mediação pedagógica desenvolvida durante a leitura, que transcorreu por cerca da metade do tempo total. Dada a restrição de tamanho para este trabalho, bem como o seu escopo, as transcrições referem-se somente às falas do professor. No entanto, entendemos que não há prejuízo para compreensão do processo ocorrido, uma vez que o professor procurava retomar, em suas falas, as falas dos estudantes que as entremeavam.

${ }^{8}$ No experimento da aula anterior, onde testávamos a condutividade elétrica de alguns materiais, um dos estudantes ficou convicto de que via a lâmpada do dispositivo de teste se acender "bem fraquinha", quando foi testado o sal de cozinha sólido.

${ }^{9}$ Aqui, e nos demais fragmentos de texto apresentados, o professor-mediador vai referir-se às suas ações em primeira pessoa.

${ }^{10} \mathrm{O}$ texto que estava sendo lido constava à página 98 . Na página 60 , tínhamos o texto “O mundo que não vemos", que discutia a ideia de modelo.

${ }^{11} \mathrm{~A}$ partir daqui, seguem-se seis turnos de falas do professor (aqui omitidos), nos quais se tem o início da discussão sobre um modelo para o funcionamento da máquina de refrigerantes.

\section{REFERÊNCIAS}

ALMEIDA, M.J.P.M.; SORPRESO, T.P. Memória e formação discursivas na interpretação de textos por estudantes de licenciatura. Revista Brasileira de Pesquisa em Educação em Ciências. São Paulo, v.10 n.1, 2010.

ANDRADE, I. B; MARTINS, I. Discursos de professores de ciências sobre leitura. Investigações em ensino de ciências, Porto Alegre, v.11 (2), p. 121- 151, 2006.

BAKHTIN, M. Para uma filosofia do ato responsável.Tradução de Valdemir Miotello e Carlos Alberto Faraco. São Carlos: João e Pedro Editores, 2010.

BAKHTIN, M.Estética da criação verbal. 4.ed. São Paulo: Martins Fontes, 2003.

BICALHO, D.C. Letramento e leitura: formando leitores críticos. In: RANGEL, E.O.; ROJO, R.H.R. (Coord.) Lingua portuguesa: ensino fundamental. Brasília: SEB/MEC, 2010. (Coleção Explorando o Ensino; v. 19)

CARNEIRO, M.H.S.; SANTOS, W.L.P.; MÓL, G.S. Livro didático inovador e professores: uma tensão a ser vencida. Ensaio: pesquisa em educação em ciências. Belo Horizonte, v.7, n.2, dez. 2005.

ESPINOZA, A. Ciências na escola: novas perspectivas para a formação dos alunos. São Paulo: Ática, 2010.

ESPINOZA, A. La especificidad de las situaciones de lectura em "naturales". 
Lectura y vida. Revista Latinoamericana de Lectura, Buenos Aires, ano 27, n.1, p. 6-16, 2006.

ESPINOZA, A.; CASAMAJOR, A.; PITTON, E. Enseñar a ler textos de ciências. Buenos Aires: Paidós, 2009.

FREITAS, M.T.A. A perspectiva vigotskiana e as tecnologias. Educação: História da Pedagogia 2 - Lev Vigotski. São Paulo, Editora Segmento, p.58-67, 2010 GIRALDI, P.M. Leitura e escrita no ensino de ciências: espaços para produção de autoria, 2010. 232 f. Tese (Doutorado em educação) - Centro de Ciências da Educação, UFSC, Florianópolis, 2010.

GERALDI, J. W. Heterocientificidade nos estudos linguísticos. In: GEGE (Org.). Palavras e contrapalavras: enfrentando questões da metodologia bakhtiana.São Carlos: Pedro e João Editores, 2012.

GERALDI, J. W. A aula como acontecimento. São Carlos: Pedro e João Editores, 2010.

GERALDI, J. W. Leitura: uma oferta de contrapalavras. In: GEGE. O espelho de Bakhtin. Campinas: Pedro e João Editores, 2007.

GERALDI, J. W. Linguagem e ensino: exercícios de militância e divulgação. Campinas: Mercado de Letras, 1996.

GERALDI, J. W.; FICHTNER, B.; BENITES, M.Transgressões convergentes: Vigotski, Bakhtin, Bateson. Campinas: Mercado de Letras, 2006.

GINZBURG, C. Mitos, emblemas, sinais: morfologia e história. São Paulo: Companhia das Letras, 1989.

GRUPO APEC. Construindo consciências:coleção de ciências para o ensino fundamental. São Paulo: Scipione, 2010.

KLEIMAN, A. Leitura: ensino e pesquisa. 2.ed. São Paulo: Pontes, 1996.

KOCH, I.G.V. Desvendando os segredosdo texto. 2.ed. São Paulo: Cortez, 2003.

LIMA, M.E.C.C.; GERALDI, C.M.G.; GERALDI, J.W. O trabalho com narrativas na investigação em educação. Educação em Revista, Belo Horizonte, v.31, n.1, 2015.

MARTINS, I. Analisando livros didáticos na perspectiva dos Estudos do Discurso:compartilhando reflexões e sugerindo uma agenda para a pesquisa. In: MARTINS, I. et al. (Ed.) Olivro didático de Ciências: contextos de exigência, critérios de seleção, práticas de leitura e uso em sala de aula.Rio de janeiro: [s.n.], 2012.

MORTIMER, E.F. Linguagem e formação de conceitos no ensino de ciências. 1. reimpr. Belo Horizonte: UFMG, 2000.

NIGRO, R.G. Textos e leitura na educação em Ciências: contribuições para alfabe $\neg$ tização científica em seu sentido mais fundamental, 2007. 290f. Tese (Doutorado em educação) - Faculdade de Educação, USP, São Paulo, 2007.

PAULA, H.F. A ciência escolar como instrumento para a compreensão da atividade científica. 2004. 359 f. Tese (Doutorado em educação) - Faculdade de Educação, UFMG, Belo Horizonte, 2004. 
PAULA, H. F.; LIMA, M.E.C.C. Formulação de questões e mediação da leitura. Investigações em ensino de ciências, Porto Alegre, v.15, n.3, p.429-461, 2010.

PAULA, H. F.; LIMA, M. E. C. C.A leitura de textos didáticos de ciências como confronto de perspectivas.Ensaio: pesquisa em educação em ciências. UFMG. FaE. CECIMIG.Belo Horizonte,Belo Horizonte, v.13, n.3, 2011.

PAIVA, A. Barrados na escola. Revista Carta Fundamental. São Paulo, n.47, 2013.

PICCININI, C.L. Imagens no ensino de Ciências: uma imagem vale mais do que mil palavras?In: MARTINS, I. et al. (Ed.) O livro didático de Ciências: contextos de exigência, critérios de seleção, práticas de leitura e uso em sala de aula. Rio de Janeiro: [s.n], 2012.

REYES, Y. Mediadores de leitura. In: FRADE, I.C.A.S.; VAL, M.G.C.; BREGUNCI, M.G.C. (org.). Glossário Ceale: termos de alfabetização, leitura e escrita para educadores. Belo Horizonte: UFMG/Faculdade de Educação, 2014.

RICON, A.E.; ALMEIDA, M.J.P.M. Ensino da física e leitura. In: Leitura: teoria e prática, Campinas, Ano 10, n. 18, dez./1991.

SILVA, H.C.; ALMEIDA, M.J.P.M. O deslocamento de aspectos do funcionamento do discurso pedagógico pela leitura de textos de divulgação científica em aulas de física. Revista Electrónica de Enseñanza de las Ciencias, Vigo, v.4, n.3, 2005.

SILVA, H.C.; ALMEIDA, M.J.P.M. Condições de Produção da leitura em aulas de Física no Ensino Médio. In: ALMEIDA, M. J. P. M.; SILVA, H.C. Linguagens, leituras e ensino de ciências. Campinas: Mercado das Letras, 1998.

SILVA, L.H.A.; SCHNETZLER, R.P. A mediação pedagógica em uma disciplina científica como referência formativa para a docência de futuros professores de biologia. Ciência e Educação,Bauru, v. 12, n. 1, p. 57-72, 2006

SILVEIRA JR., C. A mediação docente da leitura de textos didáticos para o ensino e aprendizagem de ciências nos últimos anos do Ensino Fundamental. 2015. 236 f. Tese (Doutorado em educação) - Faculdade de Educação, UFMG, Belo Horizonte, 2015.

SILVEIRA JR., C. Ler para aprender ligações químicas em aulas de ciências: investigação, reflexões e lições, 2012. 164 f.Dissertação (Mestradoem educação) - Faculdade de Educação, UFMG, Belo Horizonte, 2012.

SILVEIRA JR., C.;LIMA, M.E.C.C.; MACHADO, A.H. Análise das ligações químicas nos livros didáticos. Revista Presença Pedagógica, Belo Horizonte, v.18, n.107, p.26-31, 2012.

SMOLKA, A.L.B. A prática discursiva na sala de aula: uma perspectiva teórica e um esboço de análise. In: SIRGADO, A.P.; GÓES, M.C.R. (Org.), Pensamento e linguagem: estudos na perspectiva da psicologia soviética. 3.ed. Campinas: Cedes, 2000. (CadernosCedes24)

SOARES, M.B. As condições sociais da leitura. In: ZILBERMAN, R.; SILVA, 
E.T. (Org.). Leitura: perspectivas interdisciplinares. São Paulo: Ática, 2005. VYGOTSKY, L.S. Pensamento e da linguagem.São Paulo: Martins Fontes, 2011. VYGOTSKY, L.S. A formação social da mente.4.ed. São Paulo: Martins Fontes, 1991.

WERTSCH, J.V.; SMOLKA, A.L.B. Continuando o diálogo: Vygotsky, Bakhtin e Lotman. In: DANIELS, H. (org.). Vygotsky em foco: pressupostos e desdobramentos. Campinas: Papirus, 1994.

; DEL RÍO, P.; ALVAREZ, A. Estudos socioculturais: história, ação e mediação. In: WERTSCH, J.V.; DEL RÍO, P.; ALVAREZ, A. (Org.). Estudos socioculturais da mente. Porto Alegre: Artmed, 1998.

ZIMMERMANN, N.; SILVA, H.C. Os diferentes modos de leitura no ensino de ciência. In: CONGRESSO BRASILEIRO DE LEITURA, 16, 2007, Campinas, Anais... Campinas, 2007.

Data do recebimento: 25/03/2015

Data da aprovação: 30/09/2015

Data da versão final: $13 / 10 / 2015$

Contato:

Célio da Silveira Júnior

Rua Argentina, 94 - Bairro Naç̃oes Unidas - Sabará/MG, CEP 34590-030, celiosilveirajr@yahoo.com.br 